\title{
Rede de mentiras: a propagação de fake news na pré-campanha presidencial brasileira
}

\section{Network of lies: the spread of fake news in the Brazilian presidential pre- campaign}

\author{
Ricardo Ribeiro Ferreira*
}

*Faculdade de Letras da Universidade de Coimbra (FLUC)

Resumo

\begin{abstract}
A disseminação de conteúdo falso ou fora de contexto e seu impacto em processos de decisão das democracias ocidentais ganharam nova força com as redes sociais e voltaram a ser objeto de muitas análises, em especial depois dos resultados do referendo do Brexit e de eleições nos EUA e na Europa, em 2016 e 2017. Revisando estudos sobre estes acontecimentos e discutindo em bases teóricas e empíricas as causas e efeitos das fake news na Web 2.0, este artigo identifica a quantidade e a distribuição deste tipo de conteúdo no cenário pré-eleitoral brasileiro. Foram rastreados os links que continham os nomes dos principais possíveis candidatos à Presidência do Brasil em 2018 com o maior engajamento (compartilhamento e interações) nas redes sociais em 2017 e, após classificação utilizando critérios definidos, o desempenho das fake news foi comparado com o das notícias da mídia mainstream. Dois dados se destacam: o engajamento das fake news foi até três vezes maior que o engajamento em conteúdos de veículos de comunicação tradicionais e, nos casos dos dois melhores colocados nas pesquisas de intenção de voto até o momento da coleta de dados, situados em lados opostos do espectro ideológico, os conteúdos falsos respondem por mais da metade dos engajamentos.
\end{abstract}

Palavras-chave: fake news; notícias falsas; pós-verdade; eleições; brasil

Abstract

The dissemination of false or out-of-context content and it's impact on decision-making processes in Western democracies gained new strength with social media and became again the subject of much analysis, especially after the results of the Brexit referendum and elections in United States and Europe, in 2016 and 2017. Reviewing studies on these events and discussing the causes and effects of fake news on Web 2.0 on a theoretical and empirical basis, this article identifies the quantity and the distribution of this type of content in the Brazilian pre-electoral scenario. Links that contain the names of the main potential candidates for the 2018 presidential run with the greatest engagement (sharing and interactions) in social media in 2017 were tracked and, after classification using defined criteria, the performance of fake news was compared to the performance of mainstream media news. Two results stand out: the engagement of fake news overcame until three times the engagement of traditional media's contents and, in the cases of the two best names in the polls until the moment of data collection, located in opposite sides of the ideological spectrum, false contents accounts for more than a half of the engagements.

Keywords: fake news; post-truth; elections; brazil

\section{Introdução}

Era da pós-verdade

Políticos e instituições do Estado utilizando informações falsas ou fora de contexto não são um fenômeno recente. Há vasta documentação sobre o tema ao longo da história e a campanha de desinformação 
conduzida pelo governo Bush, que possibilitou aos Estados Unidos iniciarem a Guerra do Iraque (Castells, 2013, pp. 232-260), é um exemplo recente. Já os veículos de comunicação sempre tiveram, no mínimo, uma relação íntima com o poder político e estatal no curso de sua missão de fiscalizá-lo (Herman e Chomsky, 2002; Arbex, 2003; Castells, 2003 e 2007). Para Herman e Chomsky (2002), os mainstream media constroem narrativas, nem sempre fiéis à realidade, para manter de pé a estrutura de poder hegemônico na concepção gramsciniana e dela se beneficiar, em ordem com seus próprios interesses políticos e econômicos. Jornais, rádios e TVs, embora prestem um serviço púbico, são, em ampla maioria, empresas privadas que visam lucro (Habermas, 2012). A novidade é que cada vez mais a audiência se importa menos se as informações que recebe são exatamente o que são. Neste cenário, prosperam não apenas políticos e veículos tradicionais, mas também, mais recentemente, indivíduos e grupos, de agendas próprias, coletivas ou associadas, que passaram a ter maneiras fáceis de distribuir conteúdo fora de contexto ou falso. A queda de credibilidade da imprensa tradicional (Norris, 2011; Ladd, 2012; Nielsen, 2014) e o surgimento de novas plataformas de produção e distribuição (Castells, 2011; Siapera, 2013) contribuíram para um maior estado de relativização da verdade, com impacto direto em regimes democráticos.

Post-truth (pós-verdade) passou a integrar o Dicionário Oxford, em novembro de 2016, ao ser escolhida a palavra do ano. $O$ termo foi definido pelos editores da universidade britânica como um adjetivo "relacionado ou denotando circunstâncias nas quais fatos objetivos têm menos influência em moldar a opinião pública do que apelos a emoção e crenças pessoais" ("Word of the Year", 2016). Embora existente antes e com utilização crescente na última década, a palavra teve "pico de frequência no contexto do referendo do Brexit, no Reino Unido, e das eleições presidenciais nos Estados Unidos", em 2016. A decisão ancorada nas duas disputas políticas marcadas pela desinformação ("Art of the lie", 2016) formaliza a identidade de uma nova era da comunicação. Lideranças políticas e seus apoiadores são indiferentes à verdade dos fatos enquanto estratégias de campanhas são desenvolvidas para atender apenas aos sentimentos, desejos e medos, com a ajuda de análise de dados na internet por empresas especializadas (Cadwalladr, 2017).

Castells (2007, p. 242), à luz das transformações da sociedade em rede, afirma que "os meios de comunicação não são necessariamente os detentores do poder, mas constituem, em geral, o espaço onde o poder é decidido". E a estrutura deste espaço mudou radicalmente nos últimos anos. Dominantes no séc. $\mathrm{XX}$, o rádio e a televisão, ainda que permaneçam consideravelmente fortes, perderam terreno para a internet e, mais recentemente, para as redes sociais em particular (Newman et al., 2017). A internet multiplicou e facilitou o acesso à informação. No entanto, colocou todos na mesma arena. A convocação dos protestos que derrubaram a ditadura egípcia na Primavera Árabe trafegaram na mesma fibra ótica que notícias absurdamente falsas como "FBI agent suspected in Hillary email leaks found dead in apparent murder suicide" (Agente do FBI suspeito no vazamento de emails de Hillary é encontrado morto em aparente suicídio assassinato) ou "Pope Francis shocks world and endorses Donald Trump for president" (Papa Francisco choca o mundo e apoia Donald Trump para presidente) na corrida à Casa Branca (Silverman, 2016). Um único usuário, independente de sua credibilidade, pode atingir rapidamente tantas pessoas quanto uma consagrada rede de televisão internacional, como a CNN. Sem grande esforço laboral ou elevado custo financeiro, o conteúdo pode ser espalhado com ainda menos compromisso ético do que o visto hoje em alguns atores da mídia tradicional. 
A livre circulação de mentiras maliciosas, a ineficácia da verificação de factos, a resiliência da propaganda populista, o racismo, o sexismo e o surgimento da chamada era da pós-verdade parecem desafiar um pilar fundamental do jornalismo ético - que os fatos são importantes para a democracia e que as pessoas querem estar bem informadas quando convocadas para tomar decisões com potencial de mudar suas vidas (White, 2017, p. 14)

Antes do referendo onde a maioria dos britânicos votou por deixar a União Europeia, argumentos fora de contexto ou simplesmente falsos sobre custos de permanência e entrada de refugiados influenciaram o debate. Além do conteúdo malicioso compartilhado nas redes sociais e no discurso de políticos, a cobertura contrária à permanência no bloco, em especial a "cruzada" de tabloides, como o The Sun e o Daily Mail, e a falta de conhecimento dos cidadãos também influenciaram no resultado (Harding, 2017). Já nos EUA, a posição editorial majoritária contra Donald Trump - 360 jornais endossaram publicamente a senadora democrata Hillary Clinton, incluindo organizações de mídia sem identificação partidária e outras mais alinhadas com bandeiras conservadoras de seu rival, e apenas 11 apoiaram o republicano - não teve muito impacto (Boczkowski, 2016). Rara no jogo político do país, a vitória sem suporte da mídia, que ainda errou em não questionar mais a relação do então candidato com racistas e sexistas (Orme, 2017), evidencia perda de força e incapacidade de dialogar com os leitores. Como resume White (2017, p. 14), sobre os argumentos apresentados pelos críticos da mídia tradicional neste processo, "um sistema de imprensa e de transmissão de radio e TV profundamente falho e politizado, preso em uma bolha metropolitana, ele próprio parte da elite do establishment e incapaz de se conectar adequadamente com a frustração e com a ira de pessoas e comunidades". Estudos recentes, com coleta de dados durante a campanha, apontam um alcance elevado das notícias falsas entre os cidadãos estadunidenses e relacionam seus impactos no resultado eleitoral (Silverman, 2016; Silverman e Singer-Vine, 2016; Allcott e Gentzkow, 2017; Shao et al., 2017). É por esta razão que, entre os dois casos pilares da era da pós-verdade, este trabalho se aprofundará mais no segundo para definições e contextualização, com o objetivo de responder: (i) o fenômeno das fake news, como visto atualmente, chegou ao Brasil?; (ii) qual sua dimensão e possíveis impactos na eleição presidencial em curso? e (iii) qual a audiência que essas fake news atingem em comparação aos conteúdos de veículos de comunicação tradicionais?.

\section{Fake news: definições e contexto da produção}

Assim como os mais recentes trabalhos sobre o tema, já citados anteriormente, este artigo utiliza a definição que estabelece como fake news os textos que são intencionalmente falsos e verificáveis como falsos, e que são criados para enganar leitores. Wardle (2017) detalha sete tipos de "misinformation" ou "disinformation". De acordo com o Dicionário Oxford (2017), os dois termos se referem a "informações falsas ou imprecisas com o objetivo de enganar", mas apenas o segundo caracteriza "especialmente propaganda emitida por organização ou governo". A interpretação do trabalho de Wardle contribui para entender o surgimento e os impactos destes conteúdos, como a seguir: 
- Sátira ou paródia: sem intenção de causar mal, mas com potencial para enganar;

- Conteúdo enganoso: uso enganoso de informação para enquadrar problema ou pessoa;

- Conteúdo impostor: quando fontes genuínas são representadas;

- Conteúdo fabricado: novo conteúdo é $100 \%$ falso, projetado para enganar e fazer mal;

- Conexão falsa: quando manchetes, imagens ou legendas não suportam o conteúdo;

- Contexto falso: quando conteúdo genuíno é compartilhado com informação contextual falsa;

- Conteúdo manipulado: quando informação ou imagens genuínas são manipuladas para enganar;

Para Higgins $(2017)^{1}$, pessoas que produzem e espalham fake news são dirigidas por quatro motivações principais, o que chama de "os quatro Ps: Paixão, Política, Propaganda e Pagamento". Considerando os diferentes tipos de conteúdos com desinformação, Wardle expande e reinterpreta as motivações em oito Ps: "Poor Journalism, to Parody, to Provoke ou 'Punk', Passion, Partisanship, Profit, Political Influence ou Power e Propaganda". Ainda que se percam alguns Ps na tradução, seriam jornalismo pobre (mal feito), paródia, provocação, paixão, partidarismo, lucro, influência política ou poder e propaganda. Importante notar que um mesmo tipo de conteúdo pode ser usado por diferentes motivações, assim como um indivíduo ou grupo com uma determinada motivação pode adotar diversas práticas (quadro 1). 0 mapeamento da pesquisadora permite identificar padrões distintos entre tipos de conteúdo e fins específicos para os quais são criados.

Quadro 1: Matriz de desinformação

\begin{tabular}{|c|c|c|c|c|c|c|c|}
\hline & $\begin{array}{l}\text { Sátira ou } \\
\text { paródia }\end{array}$ & $\begin{array}{l}\text { Conexão } \\
\text { falsa }\end{array}$ & $\begin{array}{l}\text { Conteúdo } \\
\text { enganoso }\end{array}$ & $\begin{array}{l}\text { Contexto } \\
\text { falso }\end{array}$ & $\begin{array}{l}\text { Conteúdo } \\
\text { impostor }\end{array}$ & $\begin{array}{l}\text { Conteúdo } \\
\text { manipulado }\end{array}$ & $\begin{array}{l}\text { Conteúdo } \\
\text { fabricado }\end{array}$ \\
\hline Jornalismo pobre & & $\mathbf{x}$ & $\mathbf{x}$ & $\mathbf{x}$ & & & \\
\hline Parodiar & $\mathbf{x}$ & & & & $\mathbf{x}$ & & $\mathbf{x}$ \\
\hline Provocar & & & & & $\mathbf{x}$ & $\mathbf{x}$ & $\mathbf{x}$ \\
\hline Paixão & & & & $\mathbf{x}$ & & & \\
\hline Partidarismo & & & $\mathbf{x}$ & $\mathbf{x}$ & & & $\mathbf{x}$ \\
\hline Lucro & & $\mathbf{x}$ & & & $\mathbf{x}$ & & $\mathbf{x}$ \\
\hline Influência politica & & & $\mathbf{x}$ & $\mathbf{x}$ & & $\mathbf{x}$ & $\mathbf{x}$ \\
\hline Propaganda & & & $\mathbf{x}$ & $\mathbf{x}$ & $\mathbf{x}$ & $\mathbf{x}$ & $\mathbf{x}$ \\
\hline
\end{tabular}

\footnotetext{
${ }^{1}$ Eliot Higgins, jornalista britânico, usa programas de computador de código aberto e redes sociais para checagem de fatos. Destacou-se ao desmentir declarações oficiais russas em casos da guerra civil na Síria e da intervenção na Ucrânia. Verificar https://www.bellingcat.com/.
} 
Analisando a "matriz de desinformação" de Wardle (2017) percebemos que o "contexto falso" e o "conteúdo fabricado" são os mais motivantes. Ambos aparecem relacionados a propaganda e discussões políticas, mas, enquanto o primeiro tem também lugar em falhas do jornalismo e discussões de apaixonados, apenas o segundo atrai quem busca lucro. O ganho financeiro por clique de uns e o ganho político de outros são as engrenagens que movem a indústria das fake news (Subramanian, 2017; "Fake news machine", 2017; "Fake News: Baseado", 2017). Ainda segundo Subramanian (2017), investigações do BuzzFeed e do The Guardian revelaram ao menos 100 sites registrados na pequena cidade de Veles, na Macedônia, publicando notícias falsas a favor de Trump, como o indiciamento criminal de sua rival e o apoio do papa ao republicano. As páginas são construídas em uma plataforma muito comum, o WordPress, e controladas por jovens que ganham com o sistema de monetização de anúncios do Google, que paga por cada clique de um internauta em um link compartilhado no Facebook. É importante salientar que nem sempre os criadores de sites de notícias têm uma agenda política, embora seus impactos sejam aproveitados por estratégias de campanha. No caso das eleições dos EUA, alguns administradores de sites de fake news relataram ter encontrado mais demanda por material pró-Trump ou anti-Clinton e responderam entregando mais (Sydell, 2016). Quanto maior a audiência, mais recebem do Google.

Sydell (2016) rastreou uma das cinco notícias falsas mais compartilhadas durante a campanha presidencial, a morte de um agente do FBI ligado ao caso dos emails de Hillary, até um homem de 40 anos em um subúrbio de Los Angeles, mostrando que o Leste Europeu ficou famoso, mas nem tudo está lá. Do site de um jornal que nunca existiu, o DenverGuardian.com, a investigação chegou ao dono da empresa Disinfomedia, que emprega cerca de 25 "escritores" e controla uma dezena de sites nos EUA, entre eles o NationalReport.net, USAToday.com.co e WashingtonPost.com.co. Utilizar nomes parecidos com os de jornais consagrados é uma tática comum entre sites de fake news.

Nos EUA, o engajamento (número de compartilhamento e uso dos botões de reações) no Facebook dos links das principais fake news superou o engajamento das principais notícias de veículos tradicionais de comunicação do país durante os três últimos meses da campanha presidencial, de setembro a novembro de 2016 - 8,7 milhões contra 7,3 (Silverman, 2016). Em uma análise posterior, Silverman e Singer-Vine (2016) atestaram uma alta taxa de credibilidade para cinco dessas fake news. Entre os cidadãos norte-americanos entrevistados que confirmaram ter visto ao menos a manchete, de $64 \%$ a $84 \%$ afirmaram ter acreditado, variando conforme o conteúdo. Já Allcott e Gentzkow (2017), verificando apenas o movimento de notícias falsas no mesmo período, e com uma amostra maior, identificaram o total de 30 milhões de compartilhamentos em fake news pró-Trump e 8 milhões nas pró-Hillary.

Embora os motivos para sua propagação possam ser mapeados, a definição não é simples. Diferentes autores argumentam que o termo fake news é insuficiente para descrever os fenômenos complexos de mis e disinformation. Na avaliação de Zuckerman (2017), "é um termo vago e ambíguo que abrange tudo do equilíbrio falso (notícias reais que não merecem nossa atenção), propaganda (discurso armado projetado para apoiar um partido sobre outro) e desinformação (informação projetada para semear dúvidas e aumentar a desconfiança nas instituições)". Pouco mais de um ano após sua análise das eleições dos EUA, o próprio Silverman (2018) aponta para a banalização do conceito de fake news, com preocupante perda de significado e propriedade. Para o autor, considerado um dos responsáveis por trazer para e fortalecer seu uso nas análises deste processo, o termo foi "recrutado por guerras partidárias" e sua constante 
exploração o tornou mais "onipresente" e, consequentemente, "mais confuso e manipulado" ou ainda "um slogan vazio".

Há sem dúvida mais interesse, pesquisa e discussão pública sobre a desinformação e a propaganda online. No entanto, e como resultado direto da presença do fake news nos debates públicos, ele se tornou um tema politizado e polarizado (Silverman, 2018)

Deturpado o conceito, descreve Silverman (2018), fake news passou a ser usado por políticos e seus seguidores para atacar qualquer informação que não seja de seu agrado, bem como os veículos de comunicação. Erros por descuidos da imprensa foram equiparados aos conteúdos deliberadamente fabricados para suportar essas ações contra a mídia e o jornalismo. Preocupantes por si só e também indicativos da existência de problemas mais profundos na esfera pública.

A história do termo fake news simboliza como o nosso ambiente de informação atual opera e é manipulado, como a própria realidade é moldada e distorcida. É um testemunho do fato de que hoje uma frase ou imagem pode significar qualquer coisa que você quiser, desde que você tenha seguidores suficientes, disseminadores, tempo no ar, atenção - e a capacidade de coordená-los. Se você reunir esses elementos, pode literalmente rotular coisas reais como falsas. Repita uma mentira e você "fabricará" a realidade para uma parte da população. A notícia falsa significa o que sua opinião diz que ela significa (Silverman, 2018)

Nesta linha, Wardle e Derakhshan (2017) propõem uma abordagem mais ampla, sendo as fake news apenas parte de uma problemática maior a que chamam de "information disorder" (distúrbio de informação), decorrente de uma poluição informacional em escala global. Embora seja importante levar em consideração essas alterações e todas as suas implicações em um panorama macro, resulta evidente a definição categórica de fake news como informações completamente falsas, que foram criadas e divulgadas com fins lucrativos, e suas vertentes de desinformação visando ganhos políticos, com conteúdos distorcidos ou fora de contexto, desenhadas especificamente para enganar e prejudicar o leitor, conteúdos que Silverman (2018) chega a tratar como as "notícias falsas reais". Esta definição apresenta-se a mais adequada para a análise específica do presente artigo e, por tanto, a que será adotada.

\section{Mídia, poder e redes sociais}

Com a consolidação da comunicação de massa, a escolha de um candidato passou a ser definida não pelas propostas que ele defende, mas pela imagem que se tem dele. Direta ou indiretamente, campanhas e apoiadores passaram a mirar a imagem de um adversário. A "política de personalidade" rapidamente leva a uma "política de escândalos" (Castells, 2007; Tumber e Waisbord, 2004). "A destruição da credibilidade e o assassinato de personagens se tornam as armas políticas mais potentes" (Castells, 2007, p. 243). Essa guerra era essencialmente travada na televisão e dentro do conceito de news cycle (ciclo de notícias). De 
acordo com os modelos de operação de muitos estrategistas de campanhas eleitorais dos EUA, por exemplo, se uma notícia negativa, frequentemente um escândalo, for encerrada nas primeiras 24 horas, alterando-se a narrativa ou apresentando-se um outro assunto, o candidato sobrevive.

Atualizando essas análises no contexto atual, é possível perceber que não só as fake news constituem mísseis ideais para atingir a imagem de candidatos, como o campo de batalha foi ampliado da TV para a internet, onde as redes sociais são trincheiras tão ou mais eficientes. No Digital News Report 2017 do Reuters Institute, 51\% de 2.269 entrevistados nos EUA afirmaram que usam as redes sociais como fonte de notícias (Newman et al., 2017, pp. 10-11). Ainda que 66\% também tenham apontado a televisão como fonte de informação - era possível escolher mais de uma resposta - a expressividade do resultado é evidente. O Facebook foi o mais mencionado, seguido por Youtube e Twitter. No Brasil, a utilização de redes sociais para leitura de notícias é maior: $66 \%$ de 2.003 entrevistados (p. 12), com destaque para o WhatsApp em segundo, logo após o Facebook (p. 106). A penetração da internet, porém, é menor do que nos EUA (68\% da população contra 90\%, de 206 e 324 milhões, respectivamente), com uso concentrado em grandes centros urbanos e cidadãos com maior poder aquisitivo, embora esteja crescendo rapidamente (p. 106). O potencial de audiência não é o único fator que tornou plataformas como o Facebook um paraíso para campanhas de desinformação. Em seu estudo das fake news na eleição presidencial nos EUA em 2016, Allcott e Gentzkow (2017, pp. 11-12), consideram que a utilização das redes sociais também está ligada ao baixo custo fixo para produzir conteúdo, com maior "rentabilidade relativa das estratégias de pequena escala" e sem necessidade de "construir uma reputação de qualidade a longo prazo", e ao formato dessas plataformas, "fatias finas de informações vistas em telefones ou janelas de notícias, que podem dificultar a avaliação da veracidade de um artigo". Segundo levantamento conjunto de pesquisadores da Universidade Columbia e do Instituto Nacional de Pesquisa em Informática e Automação da França, 59\% dos links compartilhados nas redes sociais não são sequer abertos por quem os compartilha (Gabielkov et al., 2016, p. 5). "As pessoas se mostram mais dispostas a compartilhar um texto do que a lê-lo, formam opinião baseada em um resumo ou em um resumo de resumos" (p. 9). Para os pesquisadores, um comportamento típico do "consumo contemporâneo de informação", em que a capacidade de atenção é cada vez menor. Bakshy, Messing e Adamic (2015) mostraram que grupos de amigos no Facebook costumam ser ideologicamente segregados e que os usuários preferem ler e compartilhar notícias que estão alinhadas com ou sustentam suas posições. Além de ser mais um fator que explica o crescimento das fake news nas redes sociais, os resultados sugerem que os usuários estariam menos propensos a receber informações verdadeiras que possam condenar um artigo ideologicamente alinhado, mas falso - a própria definição da pós-verdade, como abordado anteriormente. Ao priorizar conexões com pessoas que têm as mesmas preferências e personalizar o que desejam ver em seu feed, os usuários formam o que Pariser (2011) chamou de "filtros-bolha", onde não há espaço para o contraditório. Assim, as fake news reverberam nas "câmaras de eco" (Sustein, 2001) digitais.

Para espalhar os links das notícias falsas nas redes sociais, é preciso fazer parte delas e atingir seus usuários. Messias et al. (2013) demonstraram como é fácil criar os bots (robôs), os perfis falsos, e conquistar seguidores. Com a atenção que atraíram, os jovens da Macedônia começaram a ter contas que criaram bloqueadas pelo Facebook e passaram a comprar as de usuários reais ("Fake news machine", 2017). Shao et al. (2017, p. 11) oferecem "evidência empírica quantitativa do papel fundamental desempenhado pelos bots sociais na disseminação viral de notícias falsas" nas eleições dos EUA. Ao analisar 14 milhões de 
mensagens no Twitter, os pesquisadores identificaram que "poucas contas são responsáveis por uma grande parcela do tráfego que traz conteúdo enganoso".

Essas contas são provavelmente bots, e descobrimos várias estratégias de manipulação que usam. Primeiro, os bots são particularmente ativos em amplificar notícias falsas no estágio inicial de propagação, antes que o conteúdo seja viral. Em segundo, os bots miram usuários influentes através de respostas e menções (Shao et al., 2017, p. 11).

A velocidade e o volume de postagens elevados denuncia a presença de grupos controlando os perfis, por vezes com programas de computador para postagens automáticas. No entanto, neste caso, as notícias falsas aparentam ser apenas uma das ferramentas dos interessados em direcionar discussões na rede, tenham eles relação direta com os criadores dos sites que hospedam esses artigos ou não. Análise de Lawrence (2015) identificou ao menos 20.500 contas no Twitter emitindo mensagens favoráveis ao governo da Rússia. O Senado dos EUA investiga a russa Internet Research Agency (IRA) por interferência nas eleições de 2016, via Twitter e Facebook, com conteúdo que "instigava a divisão no país, promovendo a hostilidade a imigrantes e negros" e que teria atingido milhões de usuários por anúncios pagos ou postagens de perfis falsos de um "exército de trolls" (Solon, 2017). Estudos científicos também identificaram campanhas de desinformação nas últimas eleições em França (Ferrara, 2017), Áustria (Fuchs, 2016) e Alemanha (Davey e Ebner, 2017), ligadas a grupos de extrema-direita. Apesar do impacto a ser considerado, convém destacar que os trabalhos consultados não comprovam uma relação direta entre as campanhas e o resultado. 0 mesmo relatório que aponta o crescimento do uso das plataformas no consumo de notícias destaca que seria um erro "supervalorizar o papel das redes sociais na vitória de Donald Trump" (Newman et al., 2017, p. 10).

Uma proporção muito maior de americanos ainda recebe suas notícias de fontes de televisão e online, que também se beneficiaram de um forte interesse pela corrida eleitoral. Mesmo aqueles que dependem mais das redes sociais teriam encontrado grande parte da notícia em seu feed proveniente de meios de comunicação tradicionais. Dois terços dos leitores de notícias em redes sociais nos EUA também assistem notícias de televisão (67\%) e dois terços também visitam sites ou aplicativos tradicionais (66\%) (Newman et al., 2017, pp. 10-11)

\section{Metodologia}

A medição da quantidade e da audiência das fake news tem consideráveis limitações. Sites que hospedam este tipo de conteúdo mudam constantemente de domínio e a circulação ocorre majoritariamente no news feed de redes sociais como Facebook e Twitter, onde os dados nem sempre são públicos e o acesso é

\footnotetext{
${ }^{2}$ Expressão que faz alusão a uma criatura do folclore escandinavo é utilizada, dentro deste contexto da internet, para identificar os perfis que atuam sistematicamente de maneira agressiva contra outros usuários na rede.
} 
controlado pelas empresas proprietárias ou, no caso da verificação de páginas/perfis específicos, pode requerer a permissão de seus administradores.

Páginas de internet podem ser estudas através da análise de conteúdo (Weare e Lin, 2000). A análise de conteúdo tem sido amplamente utilizada em pesquisas das ciências sociais, como a comunicação. Em sua abordagem tradicional, essa técnica de pesquisa é definida por Baran (2002, p. 410) como uma "descrição objetiva, sistemática e quantitativa do conteúdo da comunicação" e ainda por Bauer (2000, pp. 131-138) como uma "técnica sistemática para a codificação de conteúdo simbólico encontrado na comunicação", não apenas textos e imagens, mas também temas abordados e "características estruturais", como tamanho da mensagem, circulação e formas de distribuição.

No entanto, muitos pesquisadores têm colocado que a evolução das ferramentas da Web 2.0 e outras novas tecnologias que impactaram os formatos da comunicação demandam novos métodos de análise (por exemplo, Herring, 2009, McMillan, 2000; Mitra \& Cohen, 1999; Wakeford, 2000). Herring (2009) propõem uma abordagem mais ampla para a análise de conteúdo na internet, a que chama de "Web Content Analysis", incorporando características de outras disciplinas, mas preservando muitas das características essenciais da análise de conteúdo tradicional (figura 1).

Figura 1: Abordagens para análise de conteúdo web em Herring (2009, p. 238)

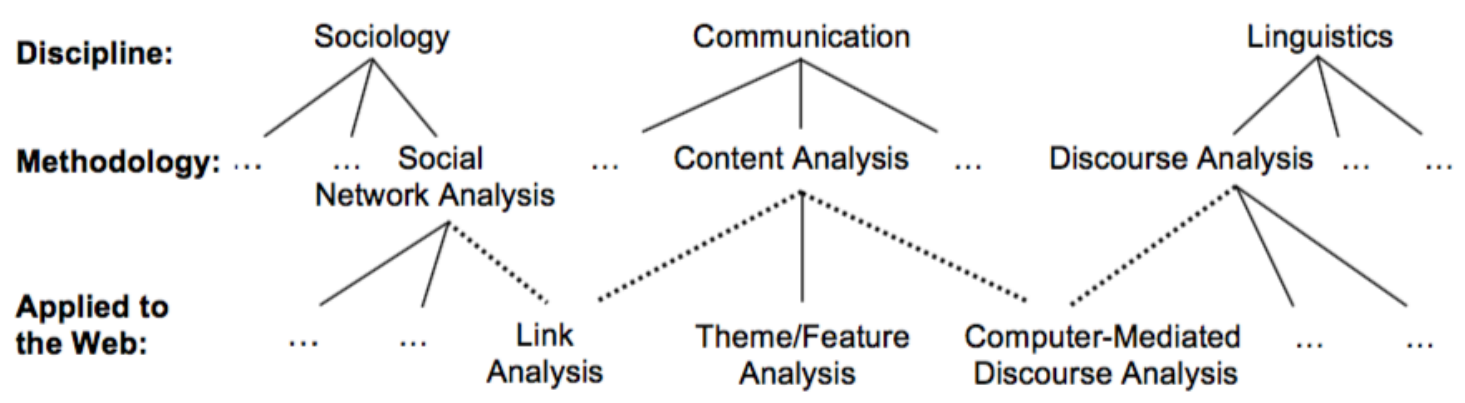

O presente artigo combina elementos da análise de link, da análise de tema e da análise de discurso, a tradicional para o conteúdo e a mediada por computador estendida especificamente para o processo de coleta da amostra, como detalharemos a seguir. Conforme em Herring (2004), que defende a utilização de programas de computador para mediar a seleção da amostra em casos de análise de discurso, estenderemos este conceito para os objetivos deste artigo e adotaremos uma ferramenta de busca de conteúdo online específica para as redes sociais, a Buzzsumo ${ }^{3}$. Buzzsumo teve sua eficiência atestada por outros estudos do tema (por exemplo, Silverman, 2016). Ao indicar uma palavra e um período de tempo específicos, a ferramenta apresenta todos os links que contenham essa palavra na composição de seu endereço eletrônico (URL) publicados nas principais redes sociais (Facebook, Twitter e Linkedin) e faz um ordenamento pela quantidade de compartilhamentos e engajamentos (o uso de botões de reação à publicação, como "like" ou "coração").

\footnotetext{
${ }^{3}$ A ferramenta encontra-se hospedada em http://buzzsumo.com.
} 
Importante observar aqui o recurso a Foot et al. (2003), também utilizado por Herring, na concepção deste modelo de paradigma expandido, que considera os links como parte do conteúdo manifesto das páginas da internet, e possíveis indicadores da credibilidade do conteúdo e até de afiliações políticas. Como já referimos, sites que hospedam fake news têm características particulares de domínio web, por exemplo, imitando nomes de veículos de mídia já estabelecidos, e este componente foi considerado na criação de categorias, bem como na classificação das amostras.

Castells (2007) observou que a disputa política é centrada na imagem dos concorrentes e, constantemente, de maneira personalizada. Tendo em linha de conta essa característica e o objetivo principal deste trabalho, a verificação do papel que desempenham as fake news em processos eleitorais de decisão e sua interferência no debate realizado na esfera pública, assim como o funcionamento da ferramenta de busca Buzzsumo, optamos por coletar as notícias que contenham os nomes dos principais concorrentes à Presidência do Brasil na eleição de 2018 em seus títulos e, logo, no link endereço URL. McMillan (2000) e Weare e Lin (2000), entre outros, defendem que a natureza dinâmica e o grande número de unidades de análise na internet tornam a amostragem aleatória inviável em muitos casos. A amostra, então, será fixa e restrita aos dez links melhores colocados, ou seja, de maior engajamento, para cada um dos quatro melhores colocados em pesquisa eleitoral de referência, visando privilegiar a análise dos conteúdos com maior potencial de influência.

Foi considerado o levantamento do instituto Datafolha mais recente no momento da coleta dos dados, realizado e divulgado em dezembro de 2017. Os principais cenários mostram a liderança de Luiz Inácio Lula da Silva, a consolidação de Jair Bolsonaro em segundo e a terceira posição disputada por Marina Silva e Geraldo Alckmin (Gielow, 2017). Preso em abril de 2018, após condenação em segunda instância por corrupção, Lula pode ter a candidatura impedida ("Lula é preso", 2018), mas há recursos em discussão e seu nome ainda figura na liderança, na casa dos 30\%, mesmo em levantamentos feitos depois da prisão (Datafolha, 2018). O primeiro turno ocorreria em outubro de 2018 e a formalização das candidaturas pelos partidos poderia ser feita até 15 de agosto (Tribunal Superior Eleitoral, 2018), o que deixava o cenário em aberto durante a conclusão deste estudo e explica o uso da nomenclatura pré-candidatos. Embora exista um número considerável de concorrentes, a presente análise faz um recorte na pesquisa para aprofundarse nos de maior possibilidade de vitória.

Os concorrentes foram buscados da maneira em que são representados em títulos de notícias com mais frequência: "Lula", "Bolsonaro", "Marina Silva" e "Alckmin". Embora mais comum nas manchetes da imprensa, o uso de apenas "Marina" gerou distorções devido a presença de conteúdos sobre a atriz brasileira Marina Ruy Barbosa. O período escolhido foi o ano de 2017, considerando engajamentos de 1 de janeiro até 18 de dezembro, dia da extração de todos os dados.

Definidas as categorias de codificação necessárias para uma análise de conteúdo (entre outros, McMillan, 2000), todos os conteúdos foram verificados utilizando técnicas previamente definidas e classificados como "falso", quando continha informações totalmente falsas, "verdadeiro", quando todo o conteúdo estava correto e completo, ou ainda "distorcido", quando misturava informações falsas ou tiradas de contexto, ou ainda quando apresentava apenas recortes de parte de um contexto maior, visando valorizar ou denegrir o candidato ator central. Uma categorização que contempla as definições de fake news e a matriz de desinformação de (Wardle, 2017). Colunas de opinião, gênero jornalístico frequentemente chamado de artigo, como definido, por exemplo, em Folha de S.Paulo (2018, pp. 128-129) foram classificadas como 
"artigo" e separadas da amostra, uma vez que candidatos podem ser atores principais de títulos e conteúdos, mas não se trata de material noticioso. Para Herring (2009, p. 235), "categorias de codificação podem surgir a partir de dados", após um estudo exploratório. É o caso das duas últimas e de um único clickbait", que será detalhado na discussão dos resultados.

Inicialmente, os textos em cada link foram desconstruídos para uma análise detalhada, conforme recomendado pelo Center for Media Literacy (Share, Jolls, \& Thoman, 2005), verificando, quando possível, os seguintes pontos: o criador da mensagem, os formatos usados para atrair a atenção, como audiência está interpretando a mensagem, valores representados ou omitidos e o seu objetivo ("porque a mensagem está sendo transmitida?"). Em um segundo momento, realizou-se uma análise do discurso, combinando seu caráter sociológico com as técnicas do jornalismo e da comunicação, extrapolando o esquema inicial de Herring (2009). Para essa classificação definitiva, então, foram realizados levantamento de dados oficiais e de outras publicações jornalísticas de referência sobre o assunto de cada conteúdo, comunicação com as fontes citadas, análises de especialistas e verificação das versões de eventuais partes acusadas. As técnicas empregadas seguiram as regras das duas maiores agências de checagem de fatos do Brasil, a Lupa ("Como a Lupa...", 2015) e a Aos Fatos ("Nosso Método", s.d.), semelhante ao utilizado na análise do contexto norte-americano por Silverman (2016), que define o processo como "desmascarar a desinformação". Parte das técnicas é própria da atividade jornalística e também foram observados o respeito aos códigos de conduta e manuais profissionais (por exemplo, Folha de S.Paulo, 2018).

As categorias pouco tradicionais para uma análise de conteúdo podem ser justificadas pela natureza do tema e do ambiente onde ocorre. A concessão para tal categorização pode ser encontrada ainda em Herring (2009, p. 235), quando o autor defende que "a mistura de canais de comunicação em sites pode exigir, especialmente, novas categorias de codificação". Embora seja uma tarefa controversa e até pretensiosa, se faz necessário para este estudo estabelecer o que é ou não verdade e entende-se que o variado conjunto de codificações e regras oferece a segurança possível para estabelecer tal definição de forma justa. Como a quantidade de notícias falsas só pode ser apontada após esse estabelecimento, temos uma metodologia mista, quantitativa, mas, de fundo, qualitativa.

Embora o uso principal da análise de conteúdo seja identificar e descrever o conteúdo manifesto, a técnica também pode ser usada para fazer inferências sobre intenções e efeitos (Holsti, 1969; Krippendorf, 1980). Neste sentido, considerando que a decisão dos eleitores é afetada pela imagem que estes formam dos candidatos por meio de notícias sobre eles (Castells, 2007) e que cresceu o número de pessoas que buscam notícias nas redes sociais (Newman et al., 2017), a identificação de uma quantidade elevada de fake news pode representar uma interferência relevante no processo eleitoral. Para tal, o total de interações dos links para conteúdos classificados como "falso", fake news pelos critérios adotados neste artigo, foi comparado com o total das interações em links de notícias de veículos de comunicação tradicionais, a mídia mainstream ou grande mídia, todos verificados como "verdadeiros". A comparação com a audiência das notícias de veículos tradicionais, tidos como mais procurados, oferece um bom parâmetro do alcance das fake news e também permite refletir sobre a crise de audiência e credibilidade da imprensa tradicional. A definição de um veículo como mainstream considera a sua elevada audiência divulgada e um maior tempo de existência

\footnotetext{
${ }^{4}$ Termo para conteúdos desenhados para atrair o clique do usuário no endereço e gerar receita de publicidade online, onde a qualidade e a precisão da informação não são prioridade, com frequente uso de manchetes sensacionalistas. Pode ser traduzido como isca de cliques ou caça-clique.
} 
da empresa, assim como a sua capacidade de influenciar grande quantidade de pessoas e governos ou mesmo de pautar veículos de menores recursos financeiros (Chomsky, 1997). Costumam refletir pensamentos dominantes e contrastam com meios alternativos ou independentes, que podem ser mais divergentes.

\section{Resultados e discussão}

Luis Inácio Lula da Silva, ex-presidente e principal liderança da esquerda no Brasil, lidera todos os cenários. No entanto, o candidato do PT (Partido dos Trabalhadores) pode ficar fora da disputa devido a uma condenação judicial, como já mencionado. Fatores que explicam o alto número de interações em conteúdos que o mencionam no título, o maior entre todos os presidenciáveis analisados, um total de 4.114.800 compartilhamentos ou reações. Destes, 2.161.300 eram em conteúdos inteiramente falsos, de sites conhecidos por publicarem fake news (gráfico 1).

Gráfico 1: Engajamento no conteúdo sobre Lula

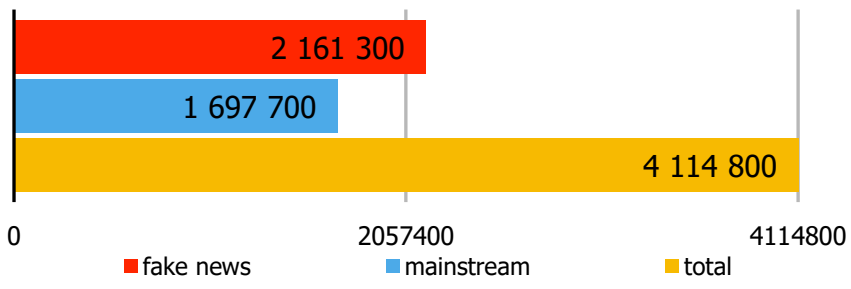

Notícias de veículos de comunicação tradicionais tiveram interação menor, um total de 1.697.700, mesmo com o impulso da cobertura da condenação de Lula em primeira instância, em julho de 2017, tema de todos os links de mídia mainstream que aparecem na lista dos dez com a maior interação (tabela 1). Um link que direcionava para uma página fora do ar foi desconsiderado, e o 110, incluído. Interessante observar que a notícia falsa "Sergio Moro proíbe Lula de concorrer a cargos públicos por 19 anos" foi publicada duas vezes em diferentes períodos, em 27 de julho e 11 de novembro, pelo site The Folha (linhas 5 e 9 do quadro 1), conhecido por criar fake news. A sentença judicial em questão suspendeu o político por sete anos, em 12 de julho. Embora até alguns veículos tradicionais tenham confundido os dados da sentença, a correção foi amplamente divulgada ainda no 12 de julho, como mostra a diferença entre título e URL do conteúdo do site mainstream "UOL" (linha 4). A insistência do "The Folha" (linha 5), republicando o erro cerca de quatro meses depois, caracteriza a intenção de enganar o leitor (Silverman, 2016; Wardle, 2017). Há ainda um artigo opinativo (linha 8), de um site de pequeno porte, que teve 225.800 interações. Não considerados noticias, artigos opinativos não foram incluídos nos gráficos comparativos deste artigo, que comparam apenas notícias verdadeiras e falsas. 
Tabela 1: Links com a palavra "Lula" de maior engajamento entre 1/1/2017 e 18/12/2017

\begin{tabular}{|c|c|c|c|}
\hline Conteúdos & Classificação & Mídia Mainstream & Engajamento total \\
\hline $\begin{array}{l}\text { Flagra de Sergio Moro após julgar Lula comove o Brasil - } \\
\text { Ele permaneceu assim por } 40 \text { minutos } \\
\text { (http://www.sociedadeoculta.com/2017/07/13/sergio- } \\
\text { moro-flagra/, de } 13 / 7 / 2017 \text { ) }\end{array}$ & Falso & Não & 1,2 milhão \\
\hline $\begin{array}{l}\text { Lula é condenado a nove anos e meio de cadeia } \\
\text { (https://veja.abril.com.br/politica/urgente-lula-e- } \\
\text { condenado-a-nove-anos-e-meio-de-cadeia/, } \\
\text { 12/7/2017) }\end{array}$ & Verdadeiro & Sim & 885 mil \\
\hline $\begin{array}{l}\text { Lula confirmado como candidato a Presidente? } \\
\text { (http://folhanacional.com/lula-confirmado-como- } \\
\text { candidato-presidente/, de 18/3/2017) }\end{array}$ & Link quebrado & - & - \\
\hline $\begin{array}{l}\text { Em sentença, Moro proíbe Lula de assumir cargos públicos } \\
\text { por } 7 \text { anos (https://noticias.uol.com.br/politica/ultimas- } \\
\text { noticias/2017/07/12/em-sentenca-moro-proibe-lula-de- } \\
\text { assumir-cargos-publicos-por-19-anos.htm, de 12/7/2017) }\end{array}$ & Verdadeiro & Sim & $338,4 \mathrm{mil}$ \\
\hline $\begin{array}{l}\text { Sergio Moro proíbe Lula de concorrer a cargos públicos por } \\
19 \text { anos (http://www.thefolha.com.br/2017/07/sergio- } \\
\text { moro-proibi-lula-de-concorrer.html, de } 27 / 7 / 2017 \text { ) }\end{array}$ & Falso & Não & 278,4 mil \\
\hline $\begin{array}{l}\text { Lula é condenado por Moro em primeiro processo na Lava } \\
\text { Jato } \quad \text { (https://noticias.uol.com.br/politica/ultimas- } \\
\text { noticias/2017/07/12/lula-e-condenado-por-moro-em- } \\
\text { primeiro-processo-na-lava-jato.htm, de 12/7/2017) }\end{array}$ & Verdadeiro & Sim & $260,1 \mathrm{mil}$ \\
\hline $\begin{array}{l}\text { Lula afirma que Marisa adoeceu por culpa da pressão do } \\
\text { povo e da Justiça (http://juntospelobrasil.com/lula-afirma- } \\
\text { que-marisa-adoeceu-por-culpa-da-pressao-do-povo-e-da- } \\
\text { justica/, de } 1 / 2 / 2017 \text { ) }\end{array}$ & Falso & Não & $259 \mathrm{mil}$ \\
\hline $\begin{array}{l}\text { O abraço de FHC em Lula ensina à internet algo precioso: } \\
\text { RESPEITO } \\
\text { (https://catracalivre.com.br/geral/cidadania/indicacao/o- } \\
\text { abraco-de-fhc-em-lula-ensina-internet-algo-precioso- } \\
\text { respeito/, de 2/2/2017) }\end{array}$ & Artigo & Não & $255,8 \mathrm{mil}$ \\
\hline $\begin{array}{l}\text { Sergio Moro proíbe Lula de concorrer a cargos públicos por } \\
19 \text { anos (http://www.thefolha.com.br/2017/10/sergio- } \\
\text { moro-proibe-lula-de-concorrer.html, de 9/11/2017) }\end{array}$ & Falso & Não & $216,7 \mathrm{mil}$ \\
\hline $\begin{array}{l}\text { Lula é condenado a } 9 \text { anos e seis meses; Moro não decreta } \\
\text { prisão } \\
\text { (http://politica.estadao.com.br/blogs/fausto-macedo/lula- }\end{array}$ & Verdadeiro & Sim & $214,2 \mathrm{mil}$ \\
\hline
\end{tabular}




\begin{tabular}{|l|l|l|l|}
\hline $\begin{array}{l}\text { e-condenado-por-moro-a-9-anos-de-prisao/, de } \\
\text { 12/7/2017) }\end{array}$ & & \\
\hline $\begin{array}{l}\text { Sergio Moro afirma: "Lula não será presidente aqui nem } \\
\text { em algum" } \\
\text { (http://www.thejornalbrasil.com.br/2017/03/sergio-moro- }\end{array}$ & Falso & Não & 207,2 mil \\
afirma-lula-nao-sera.html, de 13/5/2017) & & \\
\hline \multicolumn{2}{|r|}{ Elaborado pelo autor a partir de dados do BuzzSumo. Coleta, verificação e classificação realizadas entre 18 e 27/12/2017 } \\
\hline
\end{tabular}

Gráfico 2: Engajamento no conteúdo sobre Bolsonaro

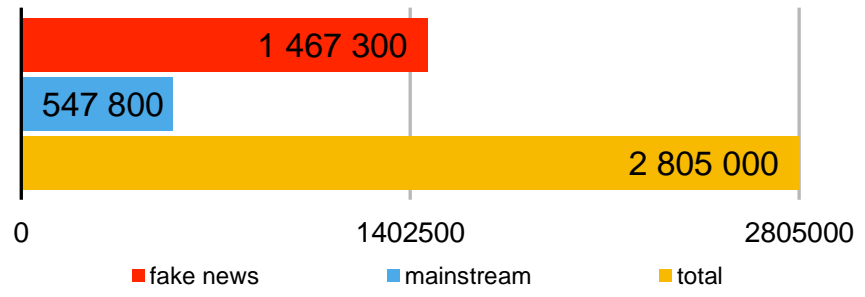

O deputado federal Jair Bolsonaro, que durante a pesquisa passou do PSC (Partido Social Cristão) para o PSL (Partido Social Liberal), é o representante de uma nova extrema-direita brasileira, que emergiu após o processo de impeachment da presidente Dilma Rousseff (PT), sucessora de Lula, e abriga também parte dos votos do chamado antipetismo e de correntes religiosas evangélicas. É o presidenciável com o maior crescimento, segundo série do Datafolha. Embora o fluxo de conteúdo seja quase a metade na comparação com Lula, total de 2.805 .000 , e tenha um link para fake news a menos, o engajamento em conteúdo falso superou o das notícias da mídia mainstream em quase o triplo (gráfico 2).

O baixo compartilhamento de links de veículos tradicionais suporta dados de Muniz (2016), que identificou, entre apoiadores de Bolsonaro, sentimento antimídia e a preferência por sites menores, frequentemente alinhados politicamente. Como em "Friboi ajudou 162 deputados, o único que recusou o dinheiro foi Jair Bolsonaro" (tabela 2, linha 2), segundo mais compartilhado, onde o título enganoso e a omissão de informações no texto favorecem a versão do deputado, que não corresponde à realidade. Ou em "Especialistas já afirmam 'Jair Bolsonaro será o presidente do Brasil"' (linha 10), que não identifica especialistas ou estudos para comprovar a premissa da manchete. O conteúdo apresenta similaridade com peças de propaganda. Ambos foram considerados fake news pela presente análise.

Tabela 2: Links com a palavra "Bolsonaro" de maior engajamento entre 1/1/2017 e 18/12/2017

\begin{tabular}{|l|l|l|l|}
\hline Conteúdos & Classificação & Mídia Mainstream & Engajamento total \\
\hline $\begin{array}{l}\text { Maria do Rosário pode tirar Bolsonaro da disputa eleitoral } \\
\text { (https://afolhabrasil.com.br/politica/acabou-maria-do- } \\
\text { rosario-tirou-bolsonaro-das-eleicoes-2018/, de 15/8/2017) }\end{array}$ & Falso & Não & 751,7 mil \\
\hline
\end{tabular}




\begin{tabular}{|c|c|c|c|}
\hline $\begin{array}{l}\text { Friboi ajudou } 162 \text { deputados, o único que recusou o } \\
\text { dinheiro foi } \quad \text { Jair } \\
\text { (http://expressodiario.com/friboi-ajudou-162-deputados- } \\
\text { o-unico-que-recusou-o-dinheiro-foi-jair-bolsonaro/, de } \\
\text { 18/3/2017) }\end{array}$ & Falso & Não & $361,1 \mathrm{mil}$ \\
\hline $\begin{array}{l}\text { Bolsonaro quer o fim do IPVA: carro não é patrimônio. } \\
\text { Assine a petição (http://juntospelobrasil.com/bolsonaro- } \\
\text { quer-o-fim-do-ipva-carro-nao-e-patrimonio-assine-a- } \\
\text { peticao/, de 17/2/2017) }\end{array}$ & Clickbait & Não & $343,7 \mathrm{mil}$ \\
\hline $\begin{array}{l}\text { Partido de Bolsonaro não vai lançá-lo como candidato a } \\
\text { presidente } \\
\text { (http://br.blastingnews.com/politica/2017/06/partido-de- } \\
\text { bolsonaro-nao-vai-lanca-lo-como-candidato-a-presidente- } \\
\text { 001784803.html, de 19/6/2017) }\end{array}$ & Artigo & Não & $243,3 \mathrm{mil}$ \\
\hline $\begin{array}{l}\text { Bolsonaro fala em mudar legislação para que PMs não } \\
\text { sejam punidos por operações } \\
\text { (http://br.blastingnews.com/politica/2017/01/bolsonaro- } \\
\text { fala-em-mudar-legislacao-para-que-pms-nao-sejam- } \\
\text { punidos-por-operacoes-001430227.html, de 29/1/2017) }\end{array}$ & Verdadeiro & Não & $202,9 \mathrm{mil}$ \\
\hline $\begin{array}{l}\text { Pesquisa aponta: Bolsonaro pode vencer no primeiro turno } \\
\text { (https://afolhabrasil.com.br/politica/pesquisa-aponta- } \\
\text { bolsonaro-pode-vencer-no-primeiro-turno/, de 26/7/2017) }\end{array}$ & Falso & Não & $197 \mathrm{mil}$ \\
\hline $\begin{array}{l}\text { Bolsonaro: 'Tenho } 5 \text { filhos. Foram } 4 \text { homens, a 5a eu dei } \\
\text { uma fraquejada e veio mulher' } \\
\text { (http://noticias.ne10.uol.com.br/politica//noticia/2017/04 } \\
\text { /06/bolsonaro-tenho-5-filhos-foram-4-homens-a-5-eu- } \\
\text { dei-uma-fraquejada-e-veio-mulher-672899.php, de } \\
\text { 6/4/2017) }\end{array}$ & Verdadeiro & Sim & $189,3 \mathrm{mil}$ \\
\hline $\begin{array}{l}\text { Bolsonaro perde recurso e é condenado a pagar } \mathrm{R} \$ 150 \\
\text { mil a fundo de defesa LGBT } \\
\text { (https://oglobo.globo.com/brasil/bolsonaro-perde- } \\
\text { recurso-e-condenado-pagar-150-mil-fundo-de-defesa- } \\
\text { lgbt-22045884, 8/11/2017) }\end{array}$ & Verdadeiro & Sim & $181,4 \mathrm{mil}$ \\
\hline $\begin{array}{l}\text { Bolsonaro quer militarizar ensino no país e pôr general no } \\
\text { MEC } \\
\text { (http://www1.folha.uol.com.br/poder/2017/08/1913223- } \\
\text { bolsonaro-quer-militarizar-ensino-no-pais-e-por-general- } \\
\text { no-mec.shtml, de 27/8/2017) }\end{array}$ & Verdadeiro & Sim & $177,1 \mathrm{mil}$ \\
\hline $\begin{array}{l}\text { Especialistas já afirmam 'Jair Bolsonaro será o presidente } \\
\text { do Brasil' } \quad \text { (https://pensabrasil.com/especialista-ja- }\end{array}$ & Falso & Não & $157,5 \mathrm{mil}$ \\
\hline
\end{tabular}




\begin{tabular}{|l|l|l|l|}
\hline $\begin{array}{l}\text { afirmam-jair-bolsonaro-sera-o-presidente-do-brasil/, de } \\
\text { 26/2/2017) }\end{array}$ & & \\
\hline \multicolumn{2}{|c|}{ Elaborado pelo autor a partir de dados do BuzzSumo. Coleta, verificação e classificação realizadas entre 18 e 27/12/2017 } \\
\hline
\end{tabular}

Há ainda um artigo, desatualizado, mas não falso, e uma espécie de reprodução de entrevista que, embora também flerte com a propaganda, baseia-se em declarações verídicas e verificadas do deputado (linha 4 da tabela 2). Já o link "Bolsonaro quer o fim do IPVA: carro não é patrimônio" é um clickbait (linha 3). É um tipo de conteúdo que deve ser entendido como desinformação (Wardle, 2017 e Wardle e Derakhshan, 2017), mas não se trata de conteúdo fabricado sobre o candidato, não contemplando integralmente a definição falso adotada da análise. $O$ texto pede que o leitor assine uma petição online pelo fim do imposto brasileiro para automóveis, comprovada como verdadeira e ativa na época, mas que não tem relação com o político. Sem menções no decorrer do conteúdo, Bolsonaro é citado apenas no título.

Marina Silva, da Rede Sustentabilidade (Rede), é a que teve o menor fluxo de conteúdo na amostra, apenas 241.000 engajamentos. Derrotada no primeiro turno da última eleição presidencial brasileira, em 2014, e sem cargos públicos, Marina passou longos períodos fora da mídia desde então. Trata-se do único caso em que os veículos tradicionais superam as fake news em número de interações, uma vez que apenas dois links foram considerados de conteúdo falso (gráfico 3).

Gráfico 3: Engajamento no conteúdo sobre Marina Silva

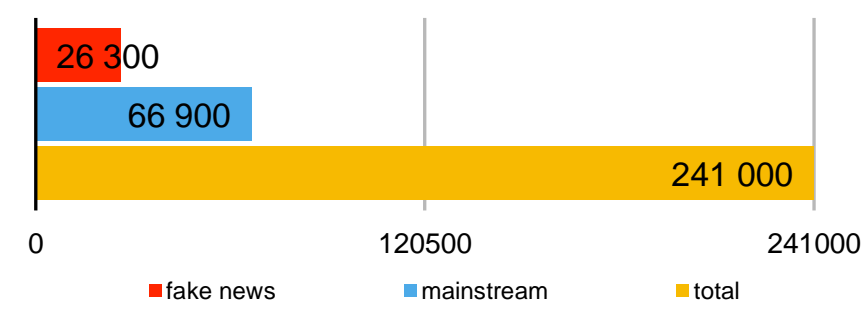

No entanto, quatro links, embora não atendam os critérios de fake news estabelecidos neste estudo, e por isso não entram na comparação do gráfico 3, continham conteúdos aparentemente desenhados para atacar a imagem de Marina e somam um engajamento relevante (tabela 3). Dois deles adotavam o "contexto falso" (Wardle, 2017) e foram classificados como "distorcido". São os dois com maior engajamento e somam 107.300, mais do que o total da mídia mainstream na amostra sobre Marina (linhas 1 e 2). Os outros dois links são artigos que recortam e debocham declarações reais dela para tecer críticas, um em um site que se declara de direita e um de esquerda (linhas 4 e 5 ).

Os resultados, ainda que registrem um baixo volume de conteúdos falsos, algo que não foi visto nos concorrentes mais presentes nas redes sociais, indicam que Marina Silva continua alvo de hostilidade, já presente na eleição de 2014 , ao se colocar como uma terceira via no radicalizado e polarizado ambiente político brasileiro. Para contexto, a Rede reúne apoiadores da proteção do ambiente, área da qual ela foi ministra de Estado, e dissidentes variados de esquerda, centro e direita. Um conteúdo de um blog de humor em que Marina não é figura principal foi desconsiderado, e o 110, incluído. 
Tabela 3: Links com "Marina Silva" de maior engajamento entre 1/1/2017 e 18/12/2017

\begin{tabular}{|c|c|c|c|}
\hline Conteúdos & Classificação & Mídia Mainstream & Engajamento total \\
\hline $\begin{array}{l}\text { Cai a hipócrita: Odebrecht delata Marina Silva: mais de } \\
\text { R\$ } 1 \text { milhão } \\
\text { (http://www.plantaobrasil.net/news.asp?nID=97193\&po } \\
=\text { s, de } 14 / 4 / 2017 \text { ) }\end{array}$ & Distorcido & Não & $56,4 \mathrm{mil}$ \\
\hline $\begin{array}{l}\text { Marina Silva embolsou meio milhão de reais de Eike } \\
\text { Batista, mesmo valor dado a Delcídio do Amaral } \\
\text { (https://www.noticiasbrasilonline.com.br/marina-silva- } \\
\text { embolsou-meio-milhao-de-reais-de-eike-batista-mesmo- } \\
\text { valor-dado-delcidio-do-amaral, de 6/2/2017) }\end{array}$ & Distorcido & Não & $50,9 \mathrm{mil}$ \\
\hline $\begin{array}{l}\text { Marina Silva: 'Nunca se juntaram por educação, saúde e } \\
\text { segurança e agora se unem para salvar a própria pele' } \\
\text { (http://www.bbc.com/portuguese/brasil-41661151, de } \\
\text { 18/10/2017) }\end{array}$ & Verdadeiro & Sim & $29,5 \mathrm{mil}$ \\
\hline $\begin{array}{l}\text { Linha auxiliar do PT, Marina Silva diz ser única solução } \\
\text { para o país (https://jornalivre.com/2017/01/11/linha- } \\
\text { auxiliar-do-pt-marina-silva-diz-ser-unica-solucao-para-o- } \\
\text { pais/, de 12/1/2017) }\end{array}$ & Artigo & Não & $21,5 \mathrm{mil}$ \\
\hline $\begin{array}{l}\text { Marina Silva: "A condenação de Lula mostra o } \\
\text { amadurecimento das instituições democráticas" } \\
\text { (http://www.diariodocentrodomundo.com.br/essencial/m } \\
\text { arina-silva-a-condenacao-de-lula-mostra-o- } \\
\text { amadurecimento-das-instituicoes-democraticas, de } \\
\text { 12/7/2017) }\end{array}$ & Artigo & Não & $19 \mathrm{mil}$ \\
\hline $\begin{array}{l}\text { FHC bate recorde de mudança de opinião e ultrapassa } \\
\text { Marina } \\
\text { (https://veja.abril.com.br/blog/sensacionalista/fhc- bate- } \\
\text { recorde-de-mudanca-de-opiniao-e-ultrapassa-marina- } \\
\text { silva/, de } 16 / 6 / 2017 \text { ) }\end{array}$ & Humor & - & - \\
\hline $\begin{array}{l}\text { REDE lança Joaquim Barbosa e Marina Silva } \\
\text { (http://juntospellobrasil.com/rede-lanca-joaquim- } \\
\text { barbosa-e-marina-silva/, 9/3/2017) }\end{array}$ & Falso & Não & $14,1 \mathrm{mil}$ \\
\hline $\begin{array}{l}\text { Marina Silva sonda Carmen Lúcia para ser sua vice } \\
\text { Elaborado pelo autor a partir de dados do BuzzSumo. } \\
\text { (https://veja.abril.com.br/blog/radar/mariina-silva-sonda- } \\
\text { carmen-lucia-para-ser-sua-vice/, de } 25 / 6 / 2017 \text { ) }\end{array}$ & $\begin{array}{l}\text { Coleta, verificação } \\
\text { Verdadeiro }\end{array}$ & $\begin{array}{l}\text { classificação realizadas } \\
\text { Sim }\end{array}$ & $\begin{array}{l}\text { entre } 18 \text { e } 27 / 12 / 2017 \\
13,7 \mathrm{mil}\end{array}$ \\
\hline $\begin{array}{l}\text { Artista pop fez } 60 \text { cirurgias para ficar igual Marina Silva } \\
\text { (http://corrupcaobrnews.org/popgirl-fez-60-cirurgias- } \\
\text { para-ficar-igual-marina-silva/, de 11/12/2017) }\end{array}$ & Falso & Não & $12,2 \mathrm{mil}$ \\
\hline
\end{tabular}




\begin{tabular}{|c|c|c|c|}
\hline $\begin{array}{l}\text { Marina Silva: "É necessária a renovação política, sem } \\
\text { negá-la" (https://exame.abril.com.br/brasil/marina-sillva- } \\
\text { e-necessaria-a-renovacao-politica-sem-nega-la/, de } \\
\text { 17/7/2017) }\end{array}$ & Verdadeiro & Sim & $12,1 \mathrm{mi}$ \\
\hline $\begin{array}{l}\text { 'Partidos não estão mais fazendo política, estão fazendo } \\
\text { negócios', diz Marina } \\
\text { (https://noticias.uol.com.br/politica/ultimas- } \\
\text { noticias/2017/07/27/partidos-nao-estao-mais-fazendo- } \\
\text { politica-estao-fazendo-negocios-diz-marina-silva.htm, de } \\
\text { 27/7/2017) }\end{array}$ & Verdadeiro & Sim & $11,6 \mathrm{mi}$ \\
\hline
\end{tabular}

Com Aécio Neves, candidato derrotado no segundo turno de 2014, envolvido em casos de corrupção, Geraldo Alckmin deve concorrer à Presidência do Brasil pelo Partido da Social Democracia Brasileira (PSDB), legenda que liderou a oposição ao governo Dilma e foi fundamental na articulação de seu impeachment. Alckmin está em seu quarto mandato como governador de São Paulo, Estado comandado pelo PSDB há mais de 20 anos. Dos dez conteúdos com seu nome no link de maior engajamento nas redes sociais, nove eram verdadeiros, sendo seis de veículos de comunicação tradicional, o maior índice do estudo (tabela 4). Um artigo com informações "em off" fez uma previsão que não se confirmou, mas não foi possível identificar se ocorreu fabricação, mau jornalismo ou revisão da decisão pelos atores envolvidos.

Tabela 4: Links com a palavra "Alckmin" de maior engajamento entre 1/1/2017 e 18/12/2017

\begin{tabular}{|c|c|c|c|}
\hline Conteúdos & Classificação & Mídia Mainstream & Engajamento total \\
\hline $\begin{array}{l}\text { 'Quem está de fuzil não quer conversar', diz Alckmin sobre } \\
\text { mortos (https://veja.abril.com.br/brasil/quem-esta-de- } \\
\text { fuzil-nao-quer-conversar-diz-alckmin-sobre-mortos/, de } \\
\text { 4/9/2017) }\end{array}$ & Verdadeiro & Sim & $89,8 \mathrm{mil}$ \\
\hline $\begin{array}{l}\text { Alckmin promete } 22 \text { novas estações do Metrô e CPTM até } \\
\text { abril do ano que vem } \\
\text { (http://jovempan.uol.com.br/programas/jornal-da- } \\
\text { manha/alckmin-promete-22-novas-estacoes-do-metro-e- } \\
\mathrm{cptm} \text {-ate-abril-do-ano-que-vem.html, de } 7 / 9 / 2017 \text { ) }\end{array}$ & Verdadeiro & Sim & $72,8 \mathrm{mil}$ \\
\hline $\begin{array}{l}\text { Cúpula do PSDB decide: Doria para presidente, ACM Neto } \\
\text { para vice: Alckmin nem foi avisado... } \\
\text { (https://br.noticias.yahoo.com/cupula-do-psdb-decide- } \\
\text { doria-para-presidente-acm-neto-para-vice-alckmin-nem- } \\
\text { foi-avisado-225741447.html, de 22/3/2017) }\end{array}$ & Artigo & Não & $63,9 \mathrm{mil}$ \\
\hline $\begin{array}{l}\text { Alckmin regulamenta lei que proíbe pancadões no estado } \\
\text { de SP (https://g1.globo.com/sao-paulo/noticia/alckmin- }\end{array}$ & Verdadeiro & Sim & $61,2 \mathrm{mil}$ \\
\hline
\end{tabular}




\begin{tabular}{|c|c|c|c|}
\hline $\begin{array}{l}\text { regulamenta-lei-que-proibe-pancadoes-no-estado-de- } \\
\text { sp.ghtml, de 16/2/2017) }\end{array}$ & & & \\
\hline $\begin{array}{l}\text { Alckmin usava cunhado para receber propina, dizem } \\
\text { delatores (https://veja.abril.com.br/politica/geraldo- } \\
\text { alckmin-usava-cunhado-para-receber-propina-da- } \\
\text { odebrecht/, de 11/4/2017) }\end{array}$ & Verdadeiro & Sim & $60,7 \mathrm{mil}$ \\
\hline $\begin{array}{l}\text { 'Eu quero ser o presidente do povo brasileiro', diz Alckmin } \\
\text { (https://noticias.uol.com.br/ultimas-noticias/agencia- } \\
\text { estado/2017/08/31/eu-quero-ser-o-presidente-do-povo- } \\
\text { brasileiro-diz-alckmin.htm, de 31/8/2017) }\end{array}$ & Verdadeiro & Sim & $57 \mathrm{mil}$ \\
\hline $\begin{array}{l}\text { Comandante da tropa de elite da polícia de Alckmin diz que } \\
\text { votaria em Bolsonaro } \\
\text { (https://noticias.uol.com.br/cotidiano/ultimas- } \\
\text { noticias/2017/08/24/comandante-da-tropa-de-elite-da- } \\
\text { policia-de-alckmin-diz-que-votaria-em-bolsonaro.htm, de } \\
\text { 24/8/2017) }\end{array}$ & Verdadeiro & $\operatorname{Sim}$ & $51,7 \mathrm{mil}$ \\
\hline $\begin{array}{l}\text { Serra e Alckmin são os maiores beneciários da Odebrecht } \\
\text { em } 22 \text { anos de hegemonia tucana em São Paulo } \\
\text { (https://theintercept.com/2017/04/20/serra-e-alckmin- } \\
\text { sao-os-maiores-beneciarios-da-odebrecht-em-22-anos- } \\
\text { de-hegemonia-tucana-em-sao-paulo/, de 20/4/2017) }\end{array}$ & Verdadeiro & Não & $48,4 \mathrm{mil}$ \\
\hline $\begin{array}{l}\text { Alckmin demite } 65 \text { músicos e desmonta Banda Sinfônica } \\
\text { (http://www.redebrasilatual.com.br/entretenimento/2017 } \\
\text { /02/alckmin-demite-65-musicos-e-desmonta-banda- } \\
\text { sinfonica, de 10/2/2017) }\end{array}$ & Verdadeiro & Não & $38,5 \mathrm{mil}$ \\
\hline $\begin{array}{l}\text { Farmacêuticos flagram trambique de Alckmin e Dória para } \\
\text { dar remédio quase vencido à população } \\
\text { (http://cartacampinas.com.br/2017/02/farmaceuticos- } \\
\text { flagram-trambique-de-alckmin-e-doria-para-dar-remedio- } \\
\text { quase-vencido-a-populacao/, de } 21 / 2 / 2017 \text { ) }\end{array}$ & Verdadeiro & Não & $37,3 \mathrm{mil}$ \\
\hline
\end{tabular}

Considerando a base teórica e os estudos empíricos utilizados neste artigo, é possível teorizar três fatores que explicariam o resultado: 1) a extensa cobertura da mídia mainstream, em maioria veículos com sede no Estado onde Alckmin atua, afasta as fake news do topo do ranking de conteúdos sobre ele; 2) há baixa produção de fake news sobre Alckmin; 3) o público que partilha conteúdo sobre ele não acessa ou prefere não compartilhar fake news. Embora as condições no campo apontem para uma combinação dos três como a reposta mais provável, outros estudos específicos seriam necessários para uma definição precisa. Cabe clarificar ainda que, nos dois últimos links da amostra sobre o governador paulista (linhas 9 e 10 da tabela 4), a maneira como os conteúdos foram apresentados pode ser discutida sob a ótica do "bias (parcialidade)" 
(Silverman, 2016) e um dos sites é conhecido por publicar fake news, mas tratam-se de informações verificadas como verdadeiras pelo estudo.

Um resultado importante que pode ser extraído da análise global da amostra é que mais da metade do engajamento total nas redes sociais para os dois pré-candidatos melhores colocados na pesquisa acontece em conteúdos falsos. Mesmo situados em lados opostos do espectro político, Lula e Bolsonaro são igualmente atingidos de maneira expressiva pelas fake news: 2.161 .300 de 4.114 .800 e 1.467 .300 de 2.805.000 engajamentos, respectivamente. Convém ressaltar ainda que o ano da coleta de dados tornouse o último em que fake news e veículos de comunicação tradicionais competiam pelo público com, eventualmente, as mesmas condições no feed de notícias do Facebook. A plataforma mudou seu algoritmo em janeiro de 2018 (Isaac, 2018), passando a priorizar publicações de usuários e a dar menos destaque aos conteúdos de páginas de imprensa. A condição eleva a relevância da análise e abre caminho para estudo comparativo.

\section{Conclusão}

Os resultados comprovam que as fake news se espalharam também no Brasil. Com a pulverização entre muitos candidatos, o cenário eleitoral adverso e um índice mais baixo de penetração da internet, o engajamento em links para conteúdo falso ainda é menor do que o verificado durante as eleições de 2016 nos EUA, alvo de muitos estudos e primeiro evento recente em que foi considerado o fenômeno em questão, mas tal engajamento é extremamente relevante e ainda alto, sobretudo na comparação da interação com o material publicado pelos veículos de comunicação tradicional. Além de demonstrar a forte propagação das notícias falsas, a análise também aponta que os usuários das redes sociais dão menos atenção para a mídia mainstream. Isso reforça a argumentação de que, no compartilhamento de um conteúdo na Web 2.0, a concordância com seu teor tem hoje mais peso do que a sua veracidade ou procedência. O engajamento das fake news sobre presidenciáveis brasileiros foi até três vezes maior do que o engajamento em conteúdos de veículos de comunicação tradicionais e, nos casos dos dois melhores colocados na pesquisa de intenção de voto, situados em lados opostos do arco ideológico local, os conteúdos falsos respondem por mais da metade dos engajamentos da amostra.

Diante do exposto, ficam respondidas as questões (i), o fenômeno das fake news, na definição aqui adotada e nos modelos recentemente identificados por pesquisadores em outros países, se propagam no Brasil, (ii) jogam papel na eleição em curso, e (iii), superam a audiência da mídia tradicional, nos principais atores da amostra. Embora não seja possível mensurar sua influência na decisão dos eleitores, o debate na esfera pública digital tem ressonância nos processos decisórios das democracias. E a eleição de 2018, a se realizar na sequência de um processo que dividiu o país, deve sofrer especial impacto. Encontra-se em andamento outro estudo deste autor para análise dos conteúdos compartilhados durante todo o ano de 2018 e, em especial, no período oficial da campanha eleitoral. Há de se considerar ainda o conteúdo transmitido pelo aplicativo WhatsApp, que tem altíssima utilização no país, mas apresenta singular desafio de mensuração. 


\section{Referências bibliográficas}

Allcott, H. e Gentzkow, M. (2017). Social media and fake news in the 2016 election. National Bureau of Economic Research. Retirado de: http://www.nber.org/papers/w23089

Arbex, J., Jr. (2003). O jornalismo canalha: a promíscua relação entre a mídia e o poder. São Paulo: Casa Amarela.

Art of the lie (2016, 10 de setembro). The Economist. Retirado de: https://www.economist.com/news/leaders/21706525-politicians-have-always-lied-does-it-matterif-they-leave-truth-behind-entirely-art?fsrc $=\mathrm{scn} / \mathrm{tw} / \mathrm{te} / \mathrm{pe} / \mathrm{ed} / \mathrm{artofthelie}$

Bakshy, E., Messing, S., e Adamic, L.A. (2015). Exposure to ideologically diverse news and opinion on Facebook. Science 348(6239),1130-1132.

Baran, S. J. (2002). Introduction to mass communication. Nova York: McGraw-Hill.

Bauer, M. (2000). Classical content analysis: A review. In M. W. Bauer \& G. Gaskell (Eds.), Qualitative researching with text, image, and sound: A practical handbook (pp. 131-151). Londres: Sage.

Boczkowski, P. (2016, 8 de novembro). Has Election 2016 been a turning point for the influence of the news media? NiemanLab. Harvard University. Retirado de: http://www.niemanlab.org/2016/11/haselection-2016-been-a-turning-point-for-the-influence-of-the-news-media/

Cadwalladr, C. (2017, 7 de maio). The great British Brexit robbery: how our democracy was hijacked. The Guardian. Retirado de: https://www.theguardian.com/technology/2017/may/07/the-great-britishbrexit-robbery-hijacked-democracy

Castells, M. (2003). A Era da Informação: Economia, Sociedade e Cultura. Volume 2: 0 Poder da Identidade. Lisboa: Fundação Calouste Gulbenkian.

Castells, M. (2007). Communication, power and counter-power in the network society. International journal of communication, 1(1), 238-266.

Castells, M. (2011). A Era da Informação: Economia, Sociedade e Cultura. Volume 1: Sociedade em Rede. Lisboa: Fundação Calouste Gulbenkian.

Castells, M. (2013). O Poder da Comunicação. Lisboa: Fundação Calouste Gulbenkian.

Chomsky, N. (1997, outubro). What Makes Mainstream Media Mainstream. Z Magazine. Retirado de: https://chomsky.info/199710 /

Como a Lupa faz suas checagens?. (2015, 15 de outubro). Agência Lupa. Retirado de: http://piaui.folha.uol.com.br/lupa/2015/10/15/como-fazemos-nossas-checagens/

Datafolha (2018, 16 de abril). Preso, Lula mantém liderança em disputa pela Presidência. Retirado de: http://datafolha.folha.uol.com.br/eleicoes/2018/04/1965039-preso-lula-mantem-lideranca-emdisputa-pela-presidencia.shtml

Davey, J. e Ebner, J. (2017). The Fringe Insurgency. Connectivity, Convergence and Mainstreaming of the Extreme Right. London: Institute for Strategic Dialogue. Retirado de: https://www.isdglobal.org/wp-content/uploads/2017/10/The-Fringe-Insurgency-221017.pdf

Dicionário Oxford (2017). Versão eletrônica. Retirado de https://en.oxforddictionaries.com

Fake news machine gears up for 2020. (2017, 12 de setembro). CNN. Retirado de: http://edition.cnn.com/videos/cnnmoney/2017/09/12/the-macedonia-story-full-subs-lon-orig.cnn 
Fake News: Baseado em fatos reais. (2017, 1 de outubro). GloboNews. Retirado de: https://globosatplay.globo.com/globonews/v/6186746/

Ferrara, E. (2017). Disinformation and Social Bot Operations in the Run Up to the 2017 French Presidential Election. Cornell University Library. Retirado de: https://arxiv.org/pdf/1707.00086.pdf

Folha de S.Paulo (2018). Manual da Redação: Folha de S.Paulo - 21a Edição. São Paulo: Publifolha

Foot, K. A., Schneider, S. M., Dougherty, M., Xenos, M., e Larsen, E. (2003). Analyzing linking practices: Candidate sites in the 2002 U.S. electoral Web sphere. Journal of Computer-Mediated Communication, 8(4). Retirado de: https://academic.oup.com/jcmc/article/8/4/JCMC842/4584279

Fuchs, C. (2016). Racism, nationalism and right-wing extremism online: The Austrian Presidential Election 2016 on Facebook. Momentum Quarterly, 5(3), 172-196. Retirado de: http://westminsterresearch.wmin.ac.uk/17699/1/PUBLSIHED ARTICLE 140-224-1-PB.pdf.pdf

Gabielkov, M., Ramachandran, A., Chaintreau, A., e Legout, A. (2016). Social Clicks: What and Who Gets Read on Twitter?. ACM SIGMETRICS / IFIP Performance 2016, Junho de 2016, Antibes Juan-lesPins, França. Retirado de: https://hal.inria.fr/hal-01281190

Gielow, I. (2017, 2 de dezembro). Lula lidera, e Bolsonaro se consolida em 20, aponta Datafolha. Folha de S.Paulo. Retirado de: http://www1.folha.uol.com.br/poder/2017/12/1940171-lula-lidera-ebolsonaro-se-consolida-em-2-aponta-datafolha.shtml

Habermas, J. (2012). A transformação estrutural da esfera pública: investigações sobre uma categoria da sociedade burguesa. Lisboa: Fundação Calouste Gulbenkian.

Harding, G. (2017). Media lies and Brexit. A Double Hammer-Blow to Europe and Ethical Journalism. In Ethics in the News. Ethical Journalism Network report on challenges four journalism in the posttruth era (11-13). Londres: Ethical Journalism Network.

Herman, E. S. e Chomsky, N. (2002). Manufacturing Consent: The Political Economy of the Mass Media. Nova York: Pantheon.

Herring, S. C. (2004). Computer-mediated discourse analysis: An approach to researching online behavior. In S. A. Barab, R. Kling, \& J. H. Gray (Eds.), Designing for virtual communities in the service of learning (pp. 338-376). Nova York: Cambridge University Press.

Herring, S. C. (2009). Web Content Analysis: Expanding the Paradigm. In J. Hunsinger, M. Allen, \& L. Klastrup (Eds.), The International Handbook of Internet Research (pp. 233-249). Berlim: SpringerVerlag.

Higgins, E. (2017, 18 de janeiro). The four Ps that drives fake news [Post do Twitter]. Retirado de: https://twitter.com/eliothiggins/status/821750465306169351

Isaac, M. (2018, 11 de janeiro). Facebook Overhauls News Feed to Focus on What Friends and Family Share. The New York Times. Retirado de: https://www.nytimes.com/2018/01/11/technology/facebooknews-feed.html

Ladd, J. M. (2012). Why Americans Hate the Media and How It Matters. Princeton: Princeton University Press.

Lawrence, A. (2015, 2 de abril). Analyzing Kremlin Twitter Bots. Global Voices. Retirado de: https://globalvoices.org/2015/04/02/analyzing-kremlin-twitter-bots/ 
Lula é preso. (2018, 7 de abril). Folha de S.Paulo. Retirado de: https://www1.folha.uol.com.br/poder/2018/04/lula-e-preso.shtml

McMillan, S. J. (2000). The microscope and the moving target: The challenge of applying content analysis to the World Wide Web. Journalism and Mass Communication Quarterly, 771), 80-98.

Messias, J., Schmidt, L., Oliveira, R., e Benevenuto, F. (2013). You followed my bot! Transforming robots into influential users in Twitter. First Monday, 18(7).

Mitra, A., e Cohen, E. (1999). Analyzing the Web: Directions and challenges. In S. Jones (Ed.), Doing internet research: Critical issues and methods for examining the net (pp. 179-202). Thousand Oaks, CA: Sage.

Muniz, D. (2016, 16 de maio). Vinte dias num grupo de WhatsApp dos apoiadores de Bolsonaro. Ponte Jornalismo. Retirado de: https://ponte.org/vinte-dias-num-grupo-de-whatsapp-dos-apoiadores-dobolsonaro/

Newman, N., Fletcher, R., Kalogeropoulos, A., Levy, D. A. L., e Nielsen, R. K. (2017). Digital News Report 2017. Oxford: Reuters Institute, University of Oxford.

Nielsen, R. K. (2014). The Many Crises of Western Journalism: A Comparative Analysis of Economic Crises, Professional Crises, and Crises of Confidence. SSRN. Retirado de: https://ssrn.com/abstract $=2600863$

Norris, P. (2011). Democratic Deficit: Critical Citizens Revisited. Cambridge: Cambridge University Press.

Nosso Método. (s.d.). Aos Fatos. Retirado de: https://aosfatos.org/nosso-m\%C3\%A9todo/.

Orme, B. (2017). Trumped: How US Media Played the Wrong Hand on Right-Wing Success. In Ethics in the News. Ethical Journalism Network report on challenges four journalism in the post-truth era (pp. 6-10). London.

Pariser, Eli. (2011). The Filter Bubble: What the Internet is Hiding from You. Londres: Penguin Books.

Shao, C., Ciampaglia, G. L., Varol, O., Flammini, A., e Menczer, F. (2017). The spread of fake news by social bots. Cornell University Library. Retirado de: https://arxiv.org/abs/1707.07592

Share, J., Jolls, T., e Thoman, E. (2005). Five key questions that can change the world: Classroom activities for media literacy. Malibu: Center for Media Literacy.

Siapera, E. (2013). Platform infomediation and journalism. Culture Machine, 14, 1-28.

Silverman, C. (2016, 16 de novembro). This analysis shows how fake election news stories outperformed real news on Facebook. Buzzfeed. Retirado de: https://www.buzzfeed.com/craigsilverman/viralfake-election-news-outperformed-real-news-on-facebook

Silverman, C. (2018, 12 de janeiro) Eu ajudei a popularizar o termo "fake news", mas hoje sinto calafrios ao ouvi-lo. Buzzfeed. Retirado de: https://www.buzzfeed.com/craigsilverman/historia-fake-news

Silverman, C. e Singer-Vine, J. (2016, 7 de dezembro). Most Americans who see fake news believe it, new survey says. Buzzfeed. Retirado de: https://www.buzzfeed.com/craigsilverman/fake-news-survey

Solon, O. (2017, 31 de outubro). Russia-backed Facebook posts 'reached 126m Americans' during US election. The Guardian. Retirado de: https://www.theguardian.com/technology/2017/oct/30/facebook-russia-fake-accounts-126-million

Subramanian, S. (2017, 15 de fevereiro). Inside the Macedonian Fake-News Complex. Wired. Retirado de: https://www.wired.com/2017/02/veles-macedonia-fake-news/

Sunstein, C. (2001). Echo Chambers. Princeton: Princeton University Press. 
Sydell, L. (2016, 23 de novembro). We tracked down a fake-news creator in the suburbs. Here's what we learned. All tech considered. National Public Radio. Retirado de: http://www.npr.org/sections/alltechconsidered/2016/11/23/503146770/npr-finds-the-head-of-acovert-fake-news-operation-in-the-suburbs

Tribunal Superior Eleitoral. (2018). Calendário eleitoral - Eleições. Retirado de: http://www.tse.jus.br/eleicoes/calendario-eleitoral/calendario-eleitoral

Tumber, H. e Waisbord, S. R. (2004). Political scandals and media across democracies, Volume II. The American Behavioral Scientist, 47(9), 1143-1152.

Zuckerman, E. (2017, 30 de janeiro) Stop Saying 'Fake News' It's Not Helping. Ethanzuckerman.com. Retirado de: http://www.ethanzuckerman.com/blog/2017/01/30/stopsaying-fake-news-its-nothelping/

Wakeford, N. (2000). New media, new methodologies: Studying the Web. In D. Gauntlett (Ed.), Web.studies: Rewiring media studies for the digital age (pp. 31-42). Londres: Arnold.

Wardle, C. (2017, 16 de novembro). Fake news. It's complicated. First Draft. Shorenstein Center on Media, Politics and Public Policy. Harvard University. Retirado de: https://firstdraftnews.com/fake-newscomplicated/

Wardle, C. e Derakhshan, H. (2017). Information Disorder: Toward an interdisciplinary framework for research and policy making. Strasbourg: Council of Europe. Retirado de: https://shorensteincenter.org/wp-content/uploads/2017/10/PREMS-162317-GBR-2018-Reportde\%CC\%81sinformation.pdf?x78124

Weare, C. e Lin, W. Y. (2000). Content analysis of the world wide web - Opportunities and challenges. Social Science Computer Review, 18(3), 272-292.

White, A. (2017). Fake News. Facebook and Matters of Fact in the Post-Truth Era. In Ethics in the News. Ethical Journalism Network report on challenges four journalism in the post-truth era (pp. 14-17). Londres: Ethical Journalism Network.

Word of the Year 2016 is... (2016, 16 de novembro). Oxford Dictionaries. Retirado de: https://en.oxforddictionaries.com/word-of-the-year/word-of-the-year-2016 